\title{
Temperature Dependent Current Transport Mechanism of Photopolymer Based Al/NOA60/p-Si MPS Device
}

\section{Şadan Özden ( $\sim$ sozden@mu.edu.tr)}

Mugla Sitki Koçman University https://orcid.org/0000-0003-0716-9194

\section{Nejmettin Avcı}

Mugla Sitki Koçman University

Osman Pakma

Batman University

Afşin İshak Kariper

Erciyes University

\section{Research Article}

Keywords: Photopolymer, NOA60, MPS, Current Transport

Posted Date: November 18th, 2021

DOI: https://doi.org/10.21203/rs.3.rs-1083136/v1

License: (9) This work is licensed under a Creative Commons Attribution 4.0 International License. Read Full License

Version of Record: A version of this preprint was published at Journal of Inorganic and Organometallic Polymers and Materials on January 6th, 2022. See the published version at https://doi.org/10.1007/s10904-021-02221-9. 
Temperature dependent current transport mechanism of photopolymer based Al/NOA60/p-Si MPS device

\author{
Şadan Özden ${ }^{1 *}$, Nejmettin Avcı ${ }^{1}$, Osman Pakma², İ.Afşin Kariper ${ }^{3}$, \\ ${ }^{1}$ Mugla Sitki Koçman University, Faculty of Sciences, Department of Physics, 48000 Mugla Kotekli, Turkey \\ ${ }^{2}$ Batman University, Faculty of Sciences and Arts, Department of Physics, Batman, Turkey \\ ${ }^{3}$ Erciyes University, Faculty of Education, Kayseri, Turkey \\ https://orcid.org/0000-0003-0716-9194 \\ https://orcid.org/0000-0001-9189-1176
}

https://orcid.org/0000-0002-3098-0973

https://orcid.org/0000-0001-9127-301X

\begin{abstract}
A photopolymer based Al/NOA60/p-Si (metal-polymer-semiconductor) MPS device was fabricated and the current transport properties were investigated by using the forward bias current-voltage (I-V) characteristic in the temperature range of 80-300 K. The cross-sectional structure of polymer/semiconductor was revealed by the scanning electron microscope (SEM) image and it was seen that the NOA60 photopolymer was tidily coated on the p-Si surface. According to the I-V measurements at room temperature, the MPS device exhibits a good rectification ratio of 8140 at $\pm 1 \mathrm{~V}$. Temperature-dependent $\mathrm{I}-\mathrm{V}$ measurements $(\mathrm{I}-\mathrm{V}-\mathrm{T})$ were analyzed on the basis of thermionic emission (TE) theory and an abnormal increase in zero-bias barrier height (BH) and a decrease in ideality factor (n) was observed with increasing temperature. Additionally, two different linear regions with distinct values from the theoretical value of the Richardson constant $\left(\mathrm{A}^{*}\right)$ were observed in the conventional Richardson plot. Such deviations from ideal TE theory has been attributed to the effect of BH inhomogeneities. Gaussian distribution (GD) of BH model has applied the I-V-T results and double GD BH with mean values of $0.75 \pm 0.08 \mathrm{eV}(80-140 \mathrm{~K})$ and $1.02 \pm 0.11 \mathrm{eV}(140-300 \mathrm{~K})$ were calculated. Moreover, the A* value of 64.73 $\mathrm{A} / \mathrm{cm}^{2} \mathrm{~K}^{2}$ was calculated close to the known value of $\mathrm{p}$-Si from the modified Richardson plot. Thus, it has been concluded that the current transport of the Al/NOA60/p-Si MPS device can be explained by TE with double GD $\mathrm{BH}$ model for a wide temperature region.
\end{abstract}

\title{
Keywords:
}

Photopolymer, NOA60, MPS, Current Transport

Corresponding Author: Şadan ÖZDEN, sozden@mu.edu.tr, sadanozden@gmail.com

\section{Introduction}

Radiation curing is an important technology, especially for coatings. In contrast to conventional methods of radiation curing, no need for any evaporation and solvent. UV polymerization is currently the most used technique for radiation curing. In this method, a light-sensitive molecule named a photoinitiator is used. The final coating film is a combination of monomer and oligomers and reflects their properties. Photopolymers have a widespread application area such as 3D printing, medical, and photoresist technologies with advantages of fast curing speed, absence of volatile solvents, flexibility, etc. [1]. 
Metal-semiconductor (MS) junctions or Schottky barrier (SB) diodes, which are among the best-known semiconductor-based devices, have found many applications since their discovery and continued to be one of the popular research topics. One of the most interesting aspects of SB devices, which act as both rectifier and ohmic contacts in electronic devices, is that the oxide (MOS) or insulating layers (MIS) between the metalsemiconductor can change the device properties and gain new functional features [2-8]. Especially in recent years, MPS devices, in which polymer and similar organic materials are used as an insulating layer, have attracted attention due to their production advantages and cost reduction [9-15].

Although photopolymers have the potential to be a suitable interface material for MPS devices with the abovementioned properties, there are no MPS device studies, except for one example using NOA61 photopolymer material, recently published by the authors [16]. The UV curable NOA60 material of Norland Optics, which is preferred in applications related to optical elements due to its high light transmission and colorless [17], has been successfully used in applications such as a filter for imaging [18], microlens arrays [19,20], polymer nanoimprinting [21], WLED [22] and biochip [23].

Although all interface materials, whether polymer, insulator, or oxide, used between the metal-semiconductor junction have an improvement effect on the device by the passivation of the dangling bonds, the other effects such as interface states, series resistance and inhomogeneities of the barrier can affect the performance. In this study, a p-Si-based MPS device was produced using the UV-curable NOA60 photopolymer material of Norland Optics. The main motivation for the preparation of this device is the possibility of simplifying the production methods and reducing the cost by using the optically transparent coating and interface material from the same material. It was determined that the device prepared in Al/NOA60/p-Si configuration exhibited a rectifying behavior. I-V measurements were made in the temperature range of 80-300 K, and the effective current transmission mechanism and the factors affecting it were tried to be determined.

\section{Experimental}

MPS device where NOA60 is used as an interface were fabricated on p-Si (100) wafers. The pieces of $20 \mathrm{x} 20$ $\mathrm{mm}$ dimensions were cut from boron-doped silicon wafers and subjected to mechanical cleaning and then chemically degreased with the RCA method. This process includes boiling in $\mathrm{NH} 4 \mathrm{OH}+\mathrm{H} 2 \mathrm{O}$ and $\mathrm{HCl}+\mathrm{H} 2 \mathrm{O} 2$ with deionized water for 10 min, drying in $\mathrm{N}_{2}$ environment, and cleaning in HF: $\mathrm{H} 2 \mathrm{O}$ (1:1) solution for 30 seconds to remove unwanted contaminations and possible oxide layer on the surface. High purity aluminum was thermally evaporated with help of tungsten filament onto the backside of the Si wafer to create the ohmic contacts under the pressure of 10-7 Torr. NOA60 liquid photopolymer purchased from Norland company was coated on the polished surfaces of p-Si wafers to form a homogeneous layer. Then, the photopolymerization was performed by a UV light (the UVGL-58) at a wavelength $(\lambda)$ of $365 \mathrm{~nm}$. The sample is cured by $10 \mathrm{~mW} / \mathrm{cm}^{2}$ irradiation intensity for $60 \mathrm{~min}$. Al/NOA60/p-Si device was fabricated by the evaporation of $\mathrm{Al}$ contacts in a dotted pattern employing a $1 \mathrm{~mm}$ diameter holed mask. The production steps of the Al/NOA60/p-Si MPS device are shown in Figure 1. The I-V characteristics of the fabricated MPS device were measured in the temperature range of $80-300 \mathrm{~K}$ with the aid of a temperature-controlled ARS-DMX-1SS high performance closed-cycle cryostat and Keithley 4200 SCS parameter analyzer under the dark. The temperature of the sample was 
monitored by a GaAlAs sensor and a Lakeshore 330 autotuning temperature controller with sensitivity better than $\pm 0.1 \mathrm{~K}$.

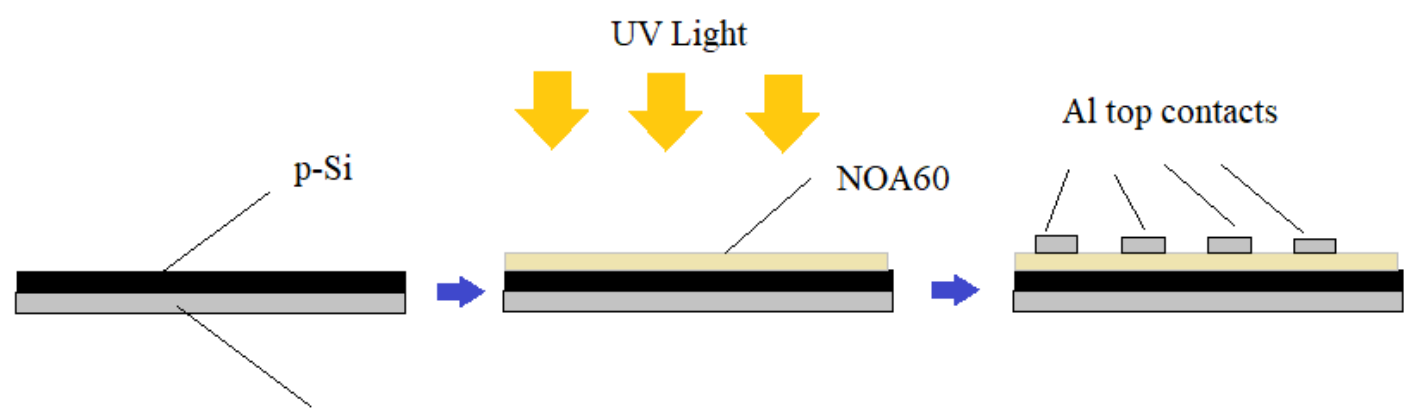

Al back contact

Fig. 1. Fabrication steps Al/NOA60/p-Si/Al MPS device.

\section{Results and Discussions}

\section{SEM analysis}

The cross-sectional structure of the coated thin photopolymer organic layer on the p-Si was investigated with the help of a JSM-7600F Schottky Field Emission SEM and is shown in Figure 2. According to image NOA60 photopolymer is tidily coated to the semiconductor surface. The thickness of the interfacial layer was calculated as about $1.59 \mu \mathrm{m}$ from the SEM image. Due to the low viscosity $\left(300 \mathrm{cps}\right.$ at $25^{\circ} \mathrm{C}$ ) of NOA 60 , an interface layer of less thickness could be obtained as a result of the coating process compared to other photopolymers in similar series.

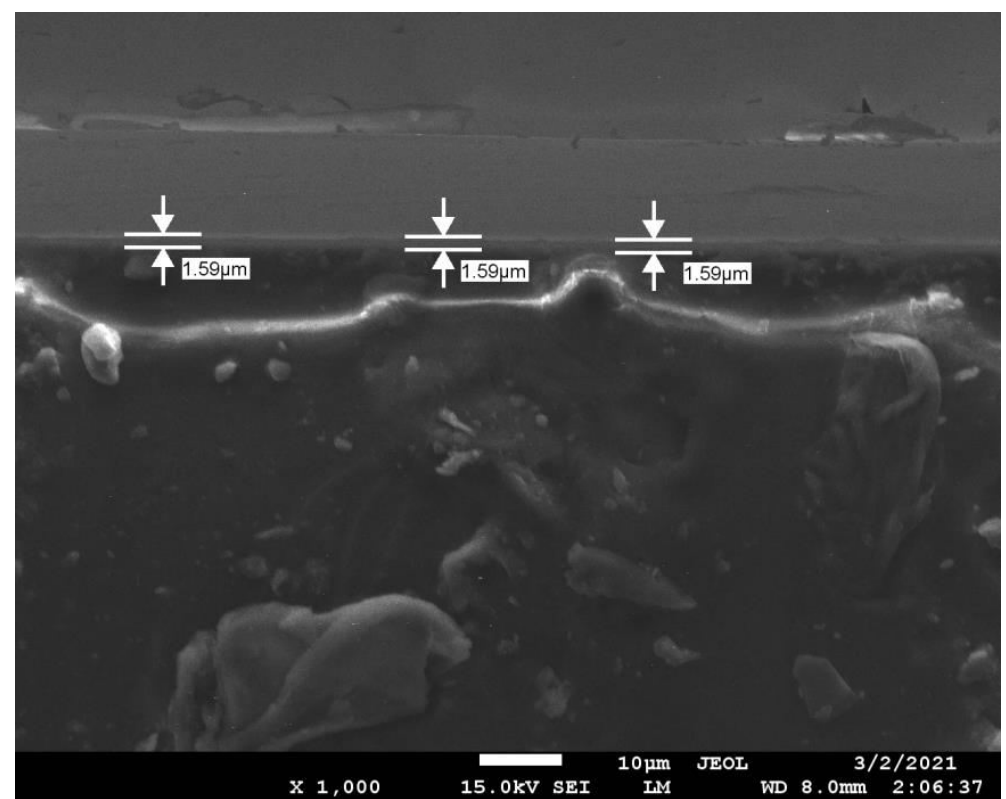

Fig. 2. The cross-section SEM image of p-Si/NOA60 interface

\section{T Dependent I-V Analysis}


The current I flowing across a MIS or MPS device under bias V is usually modeled with the help of thermionic emission theory [24-26]:

$$
I=I_{0} \exp \left(\frac{q\left(V-I R_{s}\right)}{n k T}\right)\left[1-\exp \left(\frac{q\left(V-I R_{s}\right)}{k T}\right)\right]
$$

According to this theory the I is caused by thermionic emission of the majority carriers across the Schottky barrier. The current and the barrier height, $\Phi_{\mathrm{b} 0}$ are linked by the reverse saturation current expression given below [24-26].

$$
I_{0}=A A^{*} T^{2} \exp \left(\frac{-q \Phi_{b 0}}{k T}\right)
$$

where $\mathrm{V}$ is the forward-bias voltage, $q$ is the electron charge, $\mathrm{R}_{\mathrm{S}}$ series resistance, $\mathrm{k}$ is the Boltzmann constant, $\mathrm{T}$ is the absolute temperature, $A$ is the contact area, $A^{*}$ is the effective Richardson constant of $32 \mathrm{Acm}^{-2} \mathrm{~K}^{-2}$ for $\mathrm{p}-\mathrm{Si}$. Starting from Eq. 1, ideality factor $n$ can be written as follows in regions where the $\ln I-V$ change is linear [2426]:

$$
n=\frac{q}{k T} \frac{d V}{d(\ln I)}
$$

The values of $\Phi_{b 0}$ can be extracted by using the relation,

$$
\Phi_{b 0}=\frac{k T}{q} \ln \left(\frac{A A^{*} T^{2}}{I_{0}}\right)
$$

Figure 3 shows the $\mathrm{lnI}-\mathrm{V}$ characteristic measured at room temperature (300K) for the Al/NOA60/p-Si device. The rectifier behavior of the device is quite pronounced and the rectification ratio (RR) for $\pm 1 \mathrm{~V}$ was calculated as 8140 .

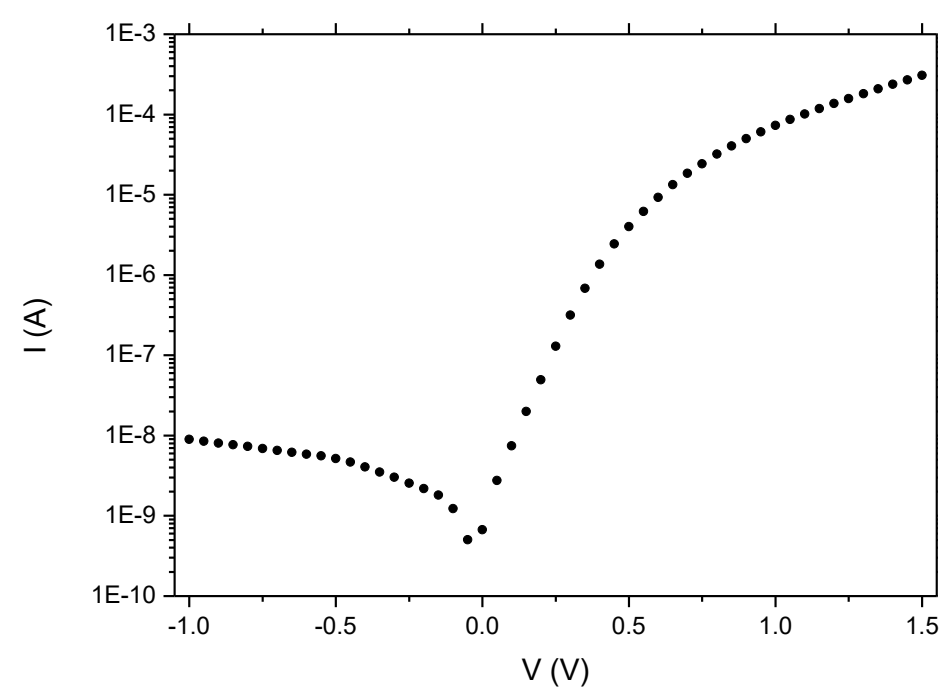


Fig.3. Room temperature (300K) lnI-V characteristics of Al/NOA60/p-Si MPS device.

In Figure 3 temperature-dependent forward bias lnI-V curves are given for the fabricated MPS device in the temperature range of $80-300 \mathrm{~K}$. When the graph is investigated, it is seen that there is a linear region at intermediate forward bias voltages. For higher bias voltages the curves deviate from linearity by the effect of series resistance and polymer interfacial layer. It is also observed that the linear region shifts to lower voltage values with increasing temperature. Similar characteristics have been reported in previous studies for MIS and MPS devices with different interface layers [26-28].

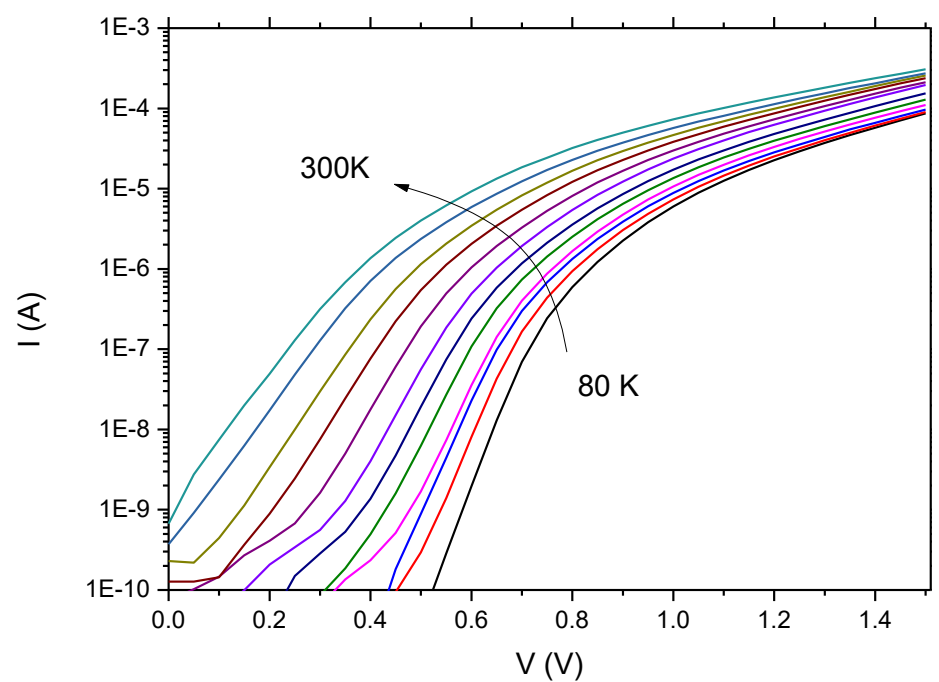

Fig.4. Temperature dependent forward bias lnI-V characteristics of Al/NOA60/p-Si MPS device.

In order to determine the possible current transport mechanism for the $\mathrm{Al} / \mathrm{NOA} 60 / \mathrm{p}-\mathrm{Si}$ device, the parameters $\mathrm{I}_{0}$, $\Phi_{b 0}$ and $\mathrm{n}$ were calculated for the region where the change of $\mathrm{InI}-\mathrm{V}$ is linear, using equations (1-4) for the different temperatures and the results are presented in Table 1.

Table1. Calculated experimental values of $\mathrm{I}_{0}, \Phi_{b 0}$ and $\mathrm{n}$ for $\mathrm{Al} / \mathrm{NOA} 60 / \mathrm{p}-\mathrm{Si}$ device

\begin{tabular}{cccc}
\hline \hline $\mathrm{T}(\mathrm{K})$ & $\mathrm{I}_{0}(\mathrm{~A})$ & $\Phi \mathrm{b}_{0}(\mathrm{eV})$ & $\mathrm{n}$ \\
\hline 80 & $2,90 \times 10^{-19}$ & 0,36 & 3,86 \\
100 & $1,57 \times 10^{-17}$ & 0,42 & 3,47 \\
120 & $1,17 \times 10^{-16}$ & 0,48 & 3,05 \\
140 & $1,19 \times 10^{-15}$ & 0,54 & 2,90 \\
160 & $8,28 \times 10^{-15}$ & 0,58 & 2,66 \\
180 & $3,85 \times 10^{-14}$ & 0,63 & 2,46 \\
200 & $1,85 \times 10^{-13}$ & 0,68 & 2,31 \\
220 & $1,15 \times 10^{-12}$ & 0,71 & 2,19 \\
240 & $1,12 \times 10^{-11}$ & 0,73 & 2,15 \\
260 & $5,27 \times 10^{-11}$ & 0,75 & 2,08 \\
280 & $3,50 \times 10^{-10}$ & 0,76 & 2,11
\end{tabular}


As can be seen in Table 1, the calculated parameters are strongly dependent on the temperature, and the values of $\mathrm{I}_{0}$ and $\Phi_{b 0}$ increase with increasing temperature, while the values of $\mathrm{n}$ decrease. The temperature dependence of $\mathrm{n}$ and $\Phi_{b 0}$ are graphically shown in Figure 5. Values of $\mathrm{n}$ greater than 1 , which is far from the ideal $(n=1)$, are generally attributed to the voltage drop on the polymer interface material, the distribution of states, and the inhomogeneity of the barrier at the polymer-semiconductor material interface [27, 29-32].

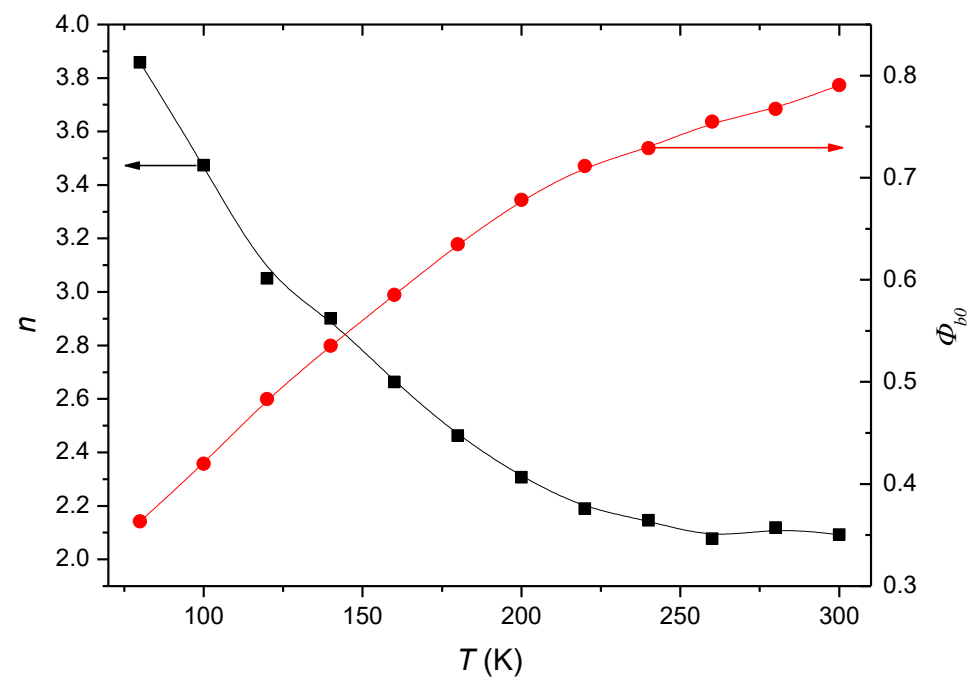

Fig. 5. Temperature dependent calculated values of $\mathrm{n}$ and $\Phi_{\mathrm{b} 0}$ of Al/NOA60/p-Si MPS device.

To explore in more detail, the temperature dependence of $n$, the graph of $n-1000 / T$ was plotted and shown in Figure 6. According to the figure, $\mathrm{n}$ takes values between 2.0 and 2.2 for the high-temperature region (240-300 $\mathrm{K}$ ) and it varies linearly with temperature below $240 \mathrm{~K}$. This linear change of $\mathrm{n}$ due to the inverse of temperature is known as the $\mathrm{T}_{0}$ anomaly, and $\mathrm{n}$ is given by the expression [33, 34],

$$
n(T)=n_{0}+\frac{T_{0}}{T}
$$

where $\mathrm{n}_{0}$ and $\mathrm{T}_{0}$ are constants and calculated as 1.36 and $205 \mathrm{~K}$, respectively. Such high values of $\mathrm{n}$ at low temperatures and its linear variation with temperature have also been reported in previous studies and explained by the inhomogeneities of the barrier height $[35,36]$. 


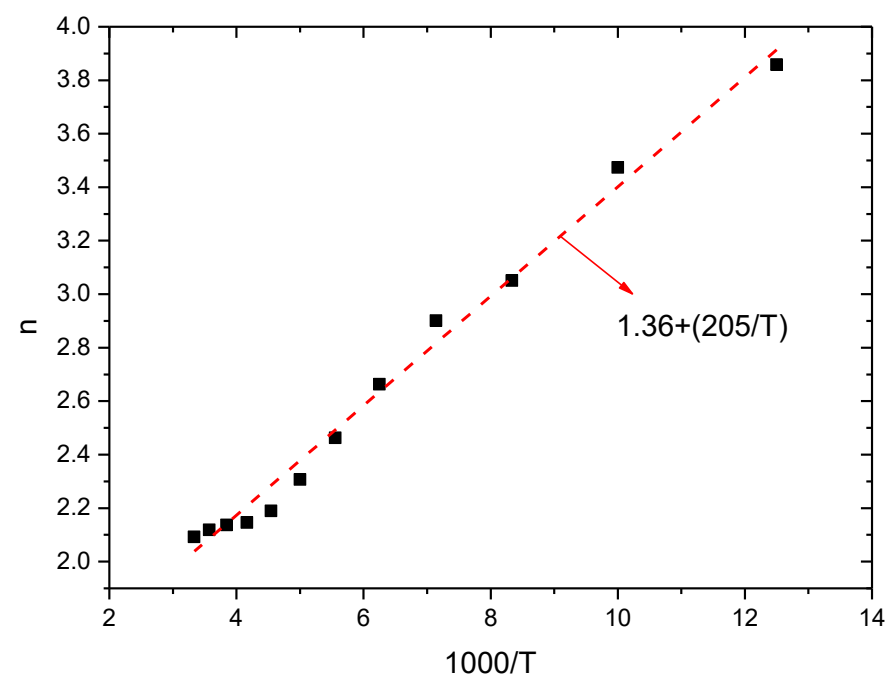

Fig.6. n-1000/T characteristics of Al/NOA60/p-Si MPS device.

The measured temperature dependent values of $I_{0}$ can be used for the calculation of $\Phi_{\mathrm{b} 0}$. These values reflect the effects of image barrier lowering and other minority carrier effects [24, 37]. According to equation (2), the plot of $\operatorname{lnI}_{0} / \mathrm{T}^{2}$ vs $1 / \mathrm{T}$ is called as Richardson plot and gives a straight line. If Eq.2 is rewritten,

$$
\ln \left(\frac{I_{0}}{T^{2}}\right)=\ln \left(A A^{*}\right)-\frac{q \Phi_{b 0}}{k T}(6)
$$

the intercept (at $1 / \mathrm{T}=0$ ) and slope of Richardson plot give $\mathrm{A}^{*}$ and $\Phi_{\mathrm{b} 0}$, respectively. However, for real MS, MIS, and MPS devices I-V curves deviate from ideal TE theory, especially for low temperatures. Some researchers have proposed modified Richardson plots to account for this deviation. The best-known of these models were summarized in the recent study by Wong et al. [37]. In the Figure 7 the ideal, $\ln _{0} / \mathrm{T}^{2}$ vs $1000 / \mathrm{T}$ and modified by the Hackam and Harrop [38], $\operatorname{lnI}_{0} / \mathrm{T}^{2}$ vs 1000/nT Richardson plots of Al/NOA60/p-Si MPS device has shown. While $\ln \mathrm{I}_{0} / \mathrm{T}^{2}-1000 / \mathrm{T}$ plot has two different linear regions as $200-300 \mathrm{~K}$ and $80-180 \mathrm{~K}, \ln _{0} / \mathrm{T}^{2}$ varies linearly with $1000 / \mathrm{nT}$ entire temperature region. According to ideal Richardson plot, the calculated $\mathrm{A}^{*}$ and $\Phi_{\mathrm{b} 0}$ values are $1.77 \times 10^{-5} \mathrm{~A} / \mathrm{cm}^{2} \mathrm{~K}^{2}, 0.42 \mathrm{eV}$ and $2.86 \times 10^{-13} \mathrm{~A} / \mathrm{cm}^{2} \mathrm{~K}^{2}, 0.12 \mathrm{eV}$ for regions $200-300 \mathrm{~K}$ and $80-180 \mathrm{~K}$, respectively. These values were obtained as $3.42 \times 10^{-4} \mathrm{~A} / \mathrm{cm}^{2} \mathrm{~K}^{2}, 1.06 \mathrm{eV}$ for the modified Richardson plot. Extracted $\mathrm{A}^{*}$ values are much lower than the known value $32 \mathrm{~A} / \mathrm{cm}^{2} \mathrm{~K}^{2}$ of the theoretical value of the Richardson constant for $\mathrm{p}$-Si. The discrepancy between the experimental and theoretical $\mathrm{A}^{*}$ values shows that these models are not adequate for calculating the $\Phi_{\mathrm{b} 0}$ of the MPS device. Such deviations have been reported in previous studies shows temperature dependency of $\Phi_{\mathrm{b} 0}$ and have been associated with spatial inhomogeneities of barrier height [39]. That is, there are low and high barrier regions at the metal-semiconductor interface and the current prefer the surmount the low barrier regions $[26,40]$. 


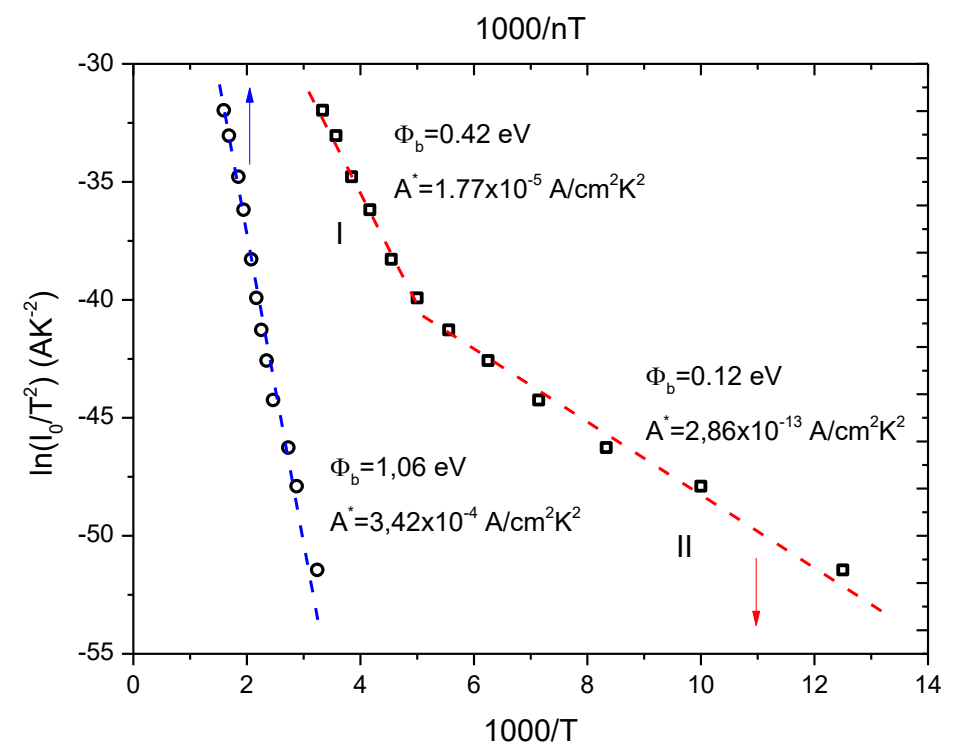

Fig.7. Richardson plots, $\ln \left(\mathrm{I}_{0} / \mathrm{T}^{2}\right)-1000 / \mathrm{T}$ and $\ln \left(\mathrm{I}_{0} / \mathrm{T}^{2}\right)-1000 / \mathrm{nT}$ of A1/NOA60/p-Si MPS device.

On the basis of the theoretical lateral inhomogeneities approach by Tung, a linear correlation between $\mathrm{n}$ and $\Phi_{\mathrm{b} 0}$ was demonstrated in the study by Schmitsdorf et al. [34, 41]. In the $\Phi_{\mathrm{b} 0}-\mathrm{n}$ plot of A1/NOA61/p-Si MPS device showed in Figure 7, two different linear regions depending on the temperature are observed. In the first region ( $80-120 \mathrm{~K}$ ) homogeneous barrier height was calculated as $0.79 \mathrm{eV}$ from extrapolation of $\Phi_{\mathrm{b} 0}-\mathrm{n}$ plot to $\mathrm{n}=1$. This value was determined as $1.02 \mathrm{eV}$ in the high temperature region $(\mathrm{T}>120 \mathrm{~K})$. These results indicate that lateral inhomogeneities are effective in the MPS device and the dominant current transport mechanism starts to deviate the ideal TE model with decreasing temperature [26, 42].

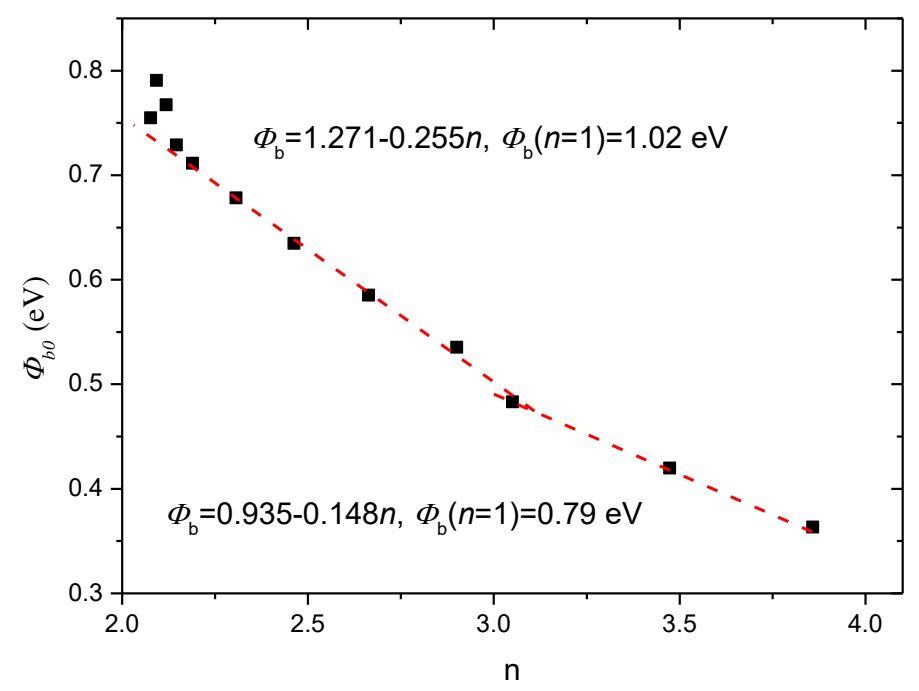

Fig.8. $\mathrm{n}$ versus $\Phi_{\mathrm{b} 0}$ graph of A1/NOA60/p-Si MPS device. 
For MPS devices that behave differently from the ideal TE theory, the I-V curves can still be described by Eq. (1) if the barrier height and ideality factor parameters are replaced by their apparent counterparts, $\mathrm{n}_{\mathrm{ap}}$ and $\Phi_{\mathrm{ap}}$. According to Gaussian Distribution (GD) model proposed by Werner and Guttler [43,44], the measured value of apparent barrier height value has given by

$$
\Phi_{a p}=\Phi_{b 0}(T=0)-\frac{q \sigma_{S}^{2}}{2 k T}(7)
$$

where $\Phi_{a p}$ is the apparent barrier height, $\Phi_{\mathrm{b} 0}$ is the mean Schottky barrier height and, $\sigma_{\mathrm{S}}$ is the standard deviation of the Gaussian distribution. The temperature dependence of $\sigma_{\mathrm{S}}$ is usually weak and can be ignored. The apparent value of $n$ has been expressed as

$$
\left(\frac{1}{n_{a p}}-1\right)=-\rho_{2}+\frac{q \rho_{3}}{2 k T}(8)
$$

where $n_{a p}$ is the apparent ideality factor, $\rho_{2}$ and $\rho_{3}$ are voltage coefficients. These voltage coefficients depend on the temperature and they quantify the deformation of the barrier height by the applied voltage. The plots of $\Phi_{\mathrm{ap}^{-}}$ q/2kT and 1/n-q/2kT depicted in Figure 9 show the existence of barrier heights with GD for the NOA60 based MPS device. The presence of three different linear regions for both graphs indicates that there are effective triple GD BHs in the MPS device. From slope and the intercept of the $\Phi_{a p}-q / 2 k T$ graphs, the BH values for these three regions were calculated as $0.75 \pm 0.08 \mathrm{eV}(80-140 \mathrm{~K}), 1.02 \pm 0.11 \mathrm{eV}(140-220 \mathrm{~K})$, and $1.00 \pm 0.11 \mathrm{eV}(220$ $300 \mathrm{~K}$ ) with their $\sigma_{\mathrm{S}}$ values. In the previous studies on MIS and MOS devices, double GD of BH was frequently reported and some of them are triple. Based on the fact that the $\mathrm{BH}$ values for the 2 nd and 3rd regions are very close to each other and the sigma values are the same, it can be said that there is mainly the double GD BH for the MPS device. The existence of two linear regions in the $\Phi_{\mathrm{b} 0}-\mathrm{n}$ graph in Figure 8 also confirms our approach.

Likewise, $\rho_{2}$ and $\rho_{3}$ values were obtained by using slope and intercept values of linear regions in the $1 / \mathrm{n}-\mathrm{q} / 2 \mathrm{kT}$ plots. All calculated values are summarized in Table 2. The results show that the ideality factor actually expresses the voltage deformation of the GD BH. The parameter $\rho_{3}$ is associated with the width of region. Accordingly, region II (140-220 K) with $1.02 \mathrm{eV} \mathrm{BH}$ is wider than region I. Where, the existence of the third region on high temperatures is more pronounced. This also shows that the applied voltage becomes more effective with increasing temperature. As a consequence, both temperature and voltage change the GD of the BH and affect the I-V characteristic of the MPS device.

Table 2. Calculated GD BH model parameters of Al/NOA60/p-Si device

\begin{tabular}{ccccc}
\hline \hline T Region & $\Phi_{\text {ap }}$ & $\sigma_{\mathrm{S}}$ & $\rho_{2}$ & $\rho_{3}$ \\
\hline $80-140 \mathrm{~K}$ & 0.75 & 0.08 & 0.539 & 0.03 \\
$140-220 \mathrm{~K}$ & 1.02 & 0.11 & 0.350 & 0.08 \\
$220-300 \mathrm{~K}$ & 1.00 & 0.11 & 0.476 & 0.02 \\
\hline
\end{tabular}




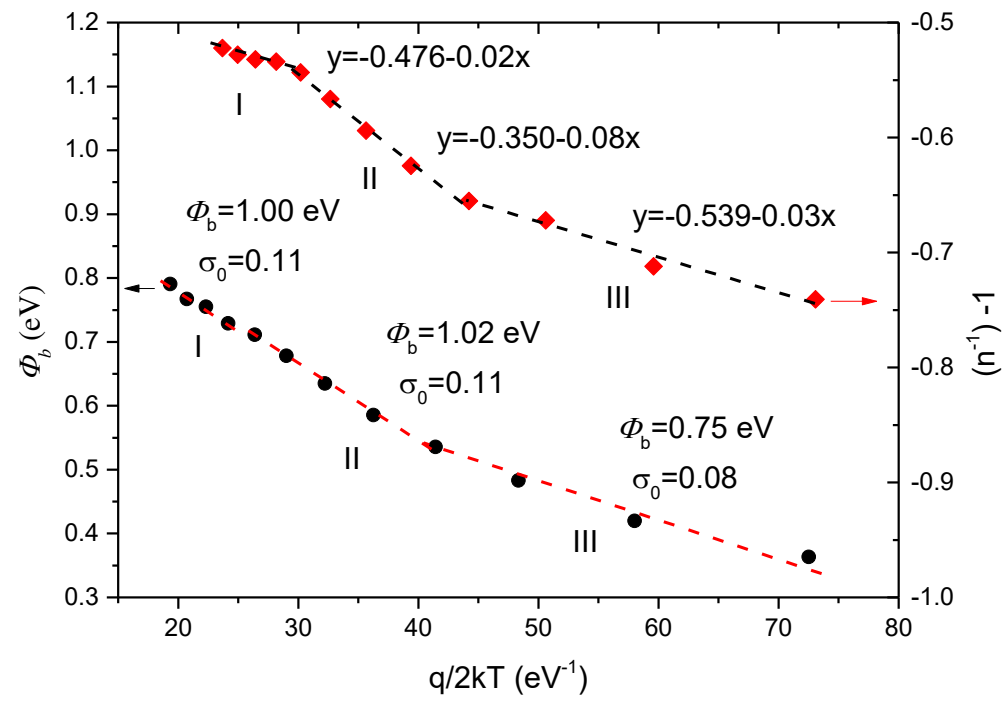

Fig.9. $n^{-1}-1$ and $\Phi_{b 0}$ vs $q / 2 k T$ graphs of Al/NOA60/p-Si MPS device for GD of BH model.

The new form of Eq. (6) can be written, considering GD of BH and using Eq. (7)

$$
\ln \left(\frac{I_{0}}{T^{2}}\right)-\left(\frac{q^{2} \sigma_{0}^{2}}{2 k^{2} T^{2}}\right)=\ln \left(A A^{*}\right)-\frac{q \Phi_{b 0}}{k T}
$$

The modified Richardson plot, $\ln \left(\mathrm{I}_{0} / \mathrm{T}^{2}\right)-\mathrm{q}^{2} \sigma_{\mathrm{S}}{ }^{2} / 2 \mathrm{k}^{2} \mathrm{~T}^{2}$ vs 1000/T of the MPS device has shown in Figure 10. As can be seen from Fig 10, there is a straight line and it slightly deviates from linearity as temperature decreases. From the slope and intercept of this linear plot mean barrier height and Richardson constant were calculated as $1.02 \mathrm{eV}$ and $64.73 \mathrm{~A} / \mathrm{cm}^{2} \mathrm{~K}^{2}$, respectively. The obtained A* value of GD BH model is close to the known value of $32 \mathrm{~A} / \mathrm{cm}^{2} \mathrm{~K}^{2}$ for $\mathrm{p}-\mathrm{Si}$ compared to other models.

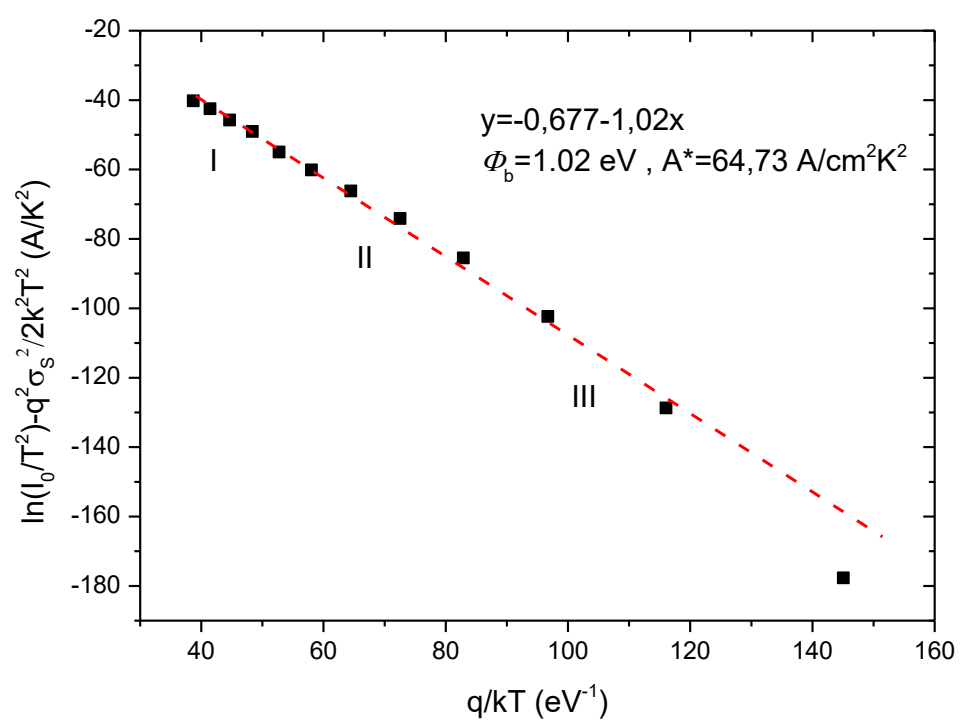

Fig. 10. Modified Richardson, $\ln \left(\mathrm{I}_{0} / \mathrm{T}^{2}\right)-\mathrm{q}^{2} \sigma_{\mathrm{S}}{ }^{2} / 2 \mathrm{k}^{2} \mathrm{~T}^{2}$ vs $1000 / \mathrm{T}$ plot of Al/NOA60/p-Si MPS device. 
Inhomogeneities of $\mathrm{BH}$ can be caused by poor interface quality, non-uniformity of surface states and dislocations, polymer layer thickness, some phase changes with temperature, and the energy band alignment of lowest molecular orbital of polymer with respect to the conduction band minimum of semiconductor [28, 39, 42, $45,46]$. Besides, the photopolymerization is not a homogeneous process. As the photopolymer film is exposed to the UV light, highly absorbed by the reactive organic monomers. According to the Lambert-Beer law, the light intensity decreases with distance from the illuminated region of the film through absorption. It gives rise to a monomer concentration gradient. The monomer molecules migrate from the bulk region towards the illuminated surface and accumulate near the illuminated surface [47]. Therefore, it may affect the polymer-semiconductor junction region.

These BH inhomogeneities have important effects on the current transport mechanism of the device. According to the results, the TE with double GD BH model emerges as the most suitable current conduction mechanism explaining the I-V-T characteristics for the MPS device.

\section{Conclusion}

NOA 60 photopolymer based MPS device with high rectification ratio of 8140 were fabricated and investigated the temperature-dependent I-V characteristics of that. According to SEM image of NOA60/p-Si interface, the photopolymer homogeneously was coated onto the semiconductor surface with about $1.5 \mu \mathrm{m}$ thickness thanks to its low viscosity. The temperature-dependent measurements show that I-V plots have a linear behavior for the low and moderate forward bias region and it deviates at the higher bias values due to the effect of the series resistance. The analysis of the region changing linearly reveals that with increasing temperature, zero bias $\mathrm{BH}$ increases and $\mathrm{n}$ decreases. It has been shown that the main reason for this behavior, which is incompatible with the TE current transport model, may be BH inhomogeneities and the GD BH approach is successful in explaining this deviation. The double GD BH with mean values of $0.75 \pm 0.08 \mathrm{eV}(80-140 \mathrm{~K})$ and $1.02 \pm 0.11 \mathrm{eV}$ $(140-300 \mathrm{~K})$ were calculated from apparent $\Phi_{\mathrm{ap}}$ and $\mathrm{n}_{\mathrm{ap}}$ expressions. Furthermore, the modified Richardson plot showed that the constant $\mathrm{A}^{*}$ was calculated as $64.73 \mathrm{~A} / \mathrm{cm}^{2} \mathrm{~K}^{2}$, which is the closest value to that of the $\mathrm{p}-\mathrm{Si}$ material. As a result, the TE current transport mechanism with double GD BH is a suitable model to explain T dependent I-V characteristics of the photopolymer based Al/NOA60/p-Si MPS device.

\section{Declarations}

\section{Funding}

The author did not receive support from any organization for the submitted work.

\section{Authors' Contributions}

All authors contributed to the study conception and design. Material preparation, data collection and analysis were performed by Şadan Özden, Nejmettin Avcı and Osman Pakma The first draft of the manuscript was written by Şadan Özden and Nejmettin Avcı and all authors commented on previous versions of the manuscript. All authors read and approved the final manuscript.

\section{Acknowledgement}


The authors would like to thank Muğla Sitkı Koçman University Research And Application Centre For Research Laboratories for their support.

\section{Conflicts of interest}

The authors declare that they have no conflict of interest.

\section{References}

[1] P. Glöckner, T. Jung, S. Struck, K. Studer, "Radiation Curing: coatings and Printing Inks; Technical Basics, Application and Trouble Shooting", European Coating Tech Files, Vincentz Network GmbH \& Co. KG, Hannover, 2008

[2] O. Pakma, N. Serin, T. Serin, and S. Altındal, "The influence of series resistance and interface states on intersecting behavior of $\mathrm{I}-\mathrm{V}$ characteristics of $\mathrm{Al} / \mathrm{TiO} 2 / \mathrm{p}-\mathrm{Si}$ (MIS) structures at low temperatures", Semicond. Sci. Technol. 23, 105014 (2008). https://doi.org/10.1088/0268-1242/23/10/105014

[3] S. Altındal, H. Kanbur, D.E. Yıldız, M. Parlak, "Current conduction mechanism in Al/p-Si Schottky barrier diodes with native insulator layer at low temperatures”, Appl. Surf. Sci., 253 pp. 5056-5061, (2007) https://doi.org/10.1016/j.apsusc.2006.11.015

[4] M.K. Hudait, S.B. Krupanidhi, "Effects of thin oxide in metal-semiconductor and metal-insulatorsemiconductor epi-GaAs Schottky diodes", Solid-State Electron., 44, 1089, (2000), https://doi.org/10.1016/S0038-1101(99)00320-2

[5] V. R. Reddy, M. S. P. Reddy, B. P. Lakshmi, A. A. Kumar, "Electrical characterization of Au/n-GaN metalsemiconductor and $\mathrm{Au} / \mathrm{SiO} 2 / \mathrm{n}-\mathrm{GaN}$ metal-insulator-semiconductor structures”, J. Alloy. Comp., 509, 8001-8007 (2011) https://doi.org/10.1016/j.jallcom.2011.05.055

[6] P. Chattopadhyay, "Effect of localized states on the current-voltage characteristics of metal-semiconductor contacts with thin interfacial layer". Solid State Electron., 37 (10), 1759-1762 (1994), https://doi.org/10.1016/0038-1101(94)90223-2

[7] S. Altındal, I. Dökme, M.M. Bülbül, N. Yalçın, T. Serin, "The role of the interface insulator layer and interface states on the current-transport mechanism of Schottky diodes in wide temperature range", Microelectron. Eng., 83, 499-505 (2006) https://doi.org/10.1016/j.mee.2005.11.014

[8] Ö. Güllü, A. Türüt, "Electrical analysis of organic dye-based MIS Schottky contacts”, Microelectron. Eng., 87, 2482-2487 (2010) https://doi.org/10.1016/j.mee.2010.05.004

[9] G. Ersöz, İ. Yücedağ, Y. Azizian-Kalandaragh, İ. Orak and Ş. Altındal, "Investigation of Electrical Characteristics in Al/CdS-PVA/p-Si (MPS) Structures Using Impedance Spectroscopy Method," IEEE Transactions on Electron Devices, 63, 7, 2948-2955 2016 https://doi.org/10.1109/TED.2016.2566813 
[10] A. Büyükbaş Uluşan, A. Tataroğlu, Y. Azizian-Kalandaragh, "On the conduction mechanisms of $\mathrm{Au} /(\mathrm{Cu} 2 \mathrm{O}-\mathrm{CuO}-\mathrm{PVA}) / \mathrm{n}-\mathrm{Si}$ (MPS) Schottky barrier diodes (SBDs) using current-voltage-temperature (I-V-T) characteristics” J Mater Sci: Mater Electron 29, 159-170 (2018). https://doi.org/10.1007/s10854-017-7900-8

[11] V. R. Reddy, "Electrical properties of Au/polyvinylidene fluoride/n-InP Schottky diode with polymer interlayer", Thin Soid Films, 556, 300-306 (2014) https://doi.org/10.1016/j.tsf.2014.01.036

[12] S. Ying, Z. Ma, Z. Zhou, R. Tao, K. Yan, M. Xin, Y. Li, L. Pan, Y. Shi. "Device Based on Polymer Schottky Junctions and Their Applications: A Review", IEEE Access, 8, 189646-189660 2020, https://doi.org/10.1109/ACCESS.2020.3030644

[13] O. Gullu, M. Cankaya, O. Baris, A. Turut, "DNA-modified indium phosphide Schottky device", Appl. Phys. Lett., 92, 212106, (2008) https://doi.org/10.1063/1.2936086

[14] A. Tataroğlu, Ş. Altındal, Y. Azizian-Kalandaragh, "Comparison of electrical properties of MS and MPS type diode in respect of (In2O3-PVP) interlayer”, Physica B: Condensed Matter, 576, 411733 (2020) https://doi.org/10.1016/j.physb.2019.411733

[15] S. Alptekin, S. O. Tan and Ş. Altındal, "Determination of Surface States Energy Density Distributions and Relaxation Times for a Metal-Polymer-Semiconductor Structure," IEEE Transactions on Nanotechnology, vol. 18, 1196-1199 2019, https://doi.org/10.1109/TNANO.2019.2952081

[16] Ş. Özden, N. Avcı, O. Pakma, A. Kariper, "NOA61 photopolymer as an interface for A1/NOA61/p-Si/Al heterojunction MPS device”, J Mater Sci: Mater Electron 32, 27688-27697 (2021). https://doi.org/10.1007/s10854-021-07150-4

[17] https://www.norlandprod.com/adhesives/NOA\%2060.html

[18] Yıldırım, E., Arpali, Ç., Arpali, S.A., "Implementation and characterization of an absorption filter for onchip fluorescent imaging, (2017),Sensor. Actuator. B Chem., 242, pp. 318323,https://doi.org/10.1016/j.snb.2016.11.029

[19] K. Kawahara, T. Kikuchi, S. Natsui, R.O. Suzuki, "Fabrication of ordered submicrometer-scale convex lens array via nanoimprint lithography using an anodized aluminum mold”, Microelectron. Eng., 185-186 (2018), pp. 61-68, https://doi.org/10.1016/j.mee.2017.10.016

[20] K. R. Kim, H. W. Jeong, K. S. Lee, J. Yi, J. C. Yoo, M. W. Cho, S. H. Cho and B. D. Choi, "Rapid laser fabrication of microlens array using colorless liquid photopolymer for AMOLED devices", Optics Communications, 284 (1) (2011) 405-410, https://doi.org/10.1016/j.optcom.2010.08.074

[21] T. Kikuchi, O. Nishinaga, S. Natsui, R.O. Suzuki, "Polymer nanoimprinting using an anodized aluminum mold for structural coloration", Appl. Surf. $\quad$ Sci., $341 \quad$ (2015), pp. 19-27, https://doi.org/10.1016/j.apsusc.2015.03.007

[22] M. Lu, X. Bai, Y. Lin, C. Ji, H. Wu, C. Ruan, W. Gao, Y. Wang, Q. Du, "Liquid-type AgInS2/ZnS quantum dot-based warm white light-emitting diodes", Chem. Phys. Lett., 661 (2016), pp. 228-233, https://doi.org/10.1016/j.cplett.2016.09.007 
[23] A.R. Prakash, S. Adamia, V. Sieben, P. Pilarski, L.M. Pilarski, C.J. Backhouse, "Small volume PCR in PDMS biochips with integrated fluid control and vapour barrier," Sensor. Actuator. B Chem., 113 (1) (2006), pp. 398-409, https://10.1016/j.snb.2005.03.049

[24] S. M. Sze and K. Ng Kwok, Physics of Semiconductor Devices, 3rd ed. (Wiley, New Jersey, 2007)

[25] E.H. Rhoderick, R.H. Williams, Metal Semiconductor Contacts, 2nd edn. (Clarendon Press, Oxford, 1988)

[26] O. Pakma, N. Serin, T. Serin, Ş. Altındal, "The double Gaussian distribution of barrier heights in $\mathrm{Al} / \mathrm{TiO} 2 / p$-Si (metal-insulator-semiconductor) structures at low temperatures“, J. Appl. Phys., 104, 014501 (2008) https://doi.org/10.1063/1.2952028

[27] S. Chand and J. Kumar, "Evidence for the double distribution of barrier heights in Schottky diodes from I V - T measurements”, J. Appl. Phys. 80, 288 (1996) https://doi.org/10.1088/0268-1242/11/8/015

[28] O. Pakma, C. Tozlu, N. Kavasoglu, S. Kavasoglu, S. Ozden, "I-V-T analysing an inhomogeneous Au/Poly(4-vinyl phenol)/p-Si structure with a double Gaussian distribution of barrier heights”, J Sol-Gel Sci Technol., 58, 244-250 (2011) https://doi.org/10.1007/s10971-010-2384-5

[29] E.E. Baydilli, S.O. Tan, H.U. Tecimer, S. Altindal, "Detection of current transport mechanisms for graphene-doped-PVA interlayered metal/semiconductor structures", Physica B, 598, 412457 (2020) https://doi.org/10.1016/j.physb.2020.412457

[30] S. Boughdachi, Y. Badali, Y. Azizian-Kalandaragh, Ş. Altındal, "Current-Transport Mechanisms of the Al/(Bi2S3-PVA Nanocomposite)/p-Si Schottky Diodes in the Temperature Range Between 220 K and 380 K”, Journal of Elec Materi 47, 6945-6953 (2018) https://doi.org/10.1007/s11664-018-6593-y

[31] A. Gümüş, Ş. Altındal, "Current-transport mechanisms in gold/polypyrrole/n-silicon Schottky barrier diodes in the temperature range of 110-360 K", Mater. Sci. Semicond. Process., 28, 66 (2014) https://doi.org/10.1016/j.mssp.2014.05.060

[32] Ş. Karataş, Ş. Altındal, A. Türüt, A. Özmen, "Temperature dependence of characteristic parameters of the H-terminated Sn/p-Si(1 0 0) Schottky contacts”, Appl. Surf. Sci., 217, 250-260 (2003)

[33] A.N. Saxena, "Forward current-voltage characteristics of Schottky barriers on n-type silicon" Surf. Sci., 13 151-171 (1969) https://doi.org/10.1016/0039-6028(69)90245-3

[34] R. T. Tung, Electron transport at metal-semiconductor interfaces: General theory, Phys. Rev. B 45, 13509 (1992) https://doi.org/10.1103/PhysRevB.45.13509

[35] S. Alialy, S. Altındal, E.E. Tanrıkulu, D.E. Yıldı, “Analysis of temperature-dependent current-conduction mechanisms in $\mathrm{Au} / \mathrm{TiO} 2 / \mathrm{n}-4 \mathrm{H}-\mathrm{SiC}$ (metal/insulator/semiconductor) type Schottky barrier diodes”, J. Appl. Phys., 116, 083709 (2014) https://doi.org/10.1063/1.4893970

[36] K. Moraki, S. Bengi, S. Zeyrek, M. M. Bülbül, Ş. Altındal, "Temperature dependence of characteristic parameters of the Au/C20H12/n-Si Schottky barrier diodes (SBDs) in the wide temperature range", J Mater Sci: Mater Electron 28, 3987-3996 (2017). https://doi.org/10.1007/s10854-016-6011-2 
[37] C. P. Y. Wong, C. Troadec, A.T. S. Wee, K. E. J. Goh, “A gaussian thermionic emission model for analysis of Au/MoS2 Schottky barrier devices”, Phys. Rev. Appl., 14, 54027 (2020) https://doi.org/10.1103/PhysRevApplied.14.054027

[38] R. Hackam, P. Harrop, "Temperature dependence of the schottky barrier height in gallium arsenide", Solid State Commun., 11, 669 (1972), https://doi.org/10.1016/0038-1098(72)90484-X

[39] İ. Taşçıoğlu, S. O. Tan, F. Yakuphanoğlu, Ş. Altındal, "Effectuality of Barrier Height Inhomogeneity on the Current-Voltage-Temperature Characteristics of Metal Semiconductor Structures with CdZnO Interlayer", Journal of Elec Materi., 47, 6059-6066 (2018) https://doi.org/10.1007/s11664-018-6495-z

[40] İ. Taşçığlu, U. Aydemir, et Ş Altındal, “The explanation of barrier height inhomogeneities in Au/n-Si Schottky barrier diodes with organic thin interfacial layer”, J. Appl. Phys., 108 (6), 064506 (2010) https://doi.org/10.1063/1.3468376

[41] R. F. Schmitsdorf, T. U. Kampen, and W. Mönch,Explanation of the linear correlation between barrier heights and ideality factors of real metal-semiconductor contacts by laterally nonuniformSchottky barriers, J. Vac. Sci. Technol. B 15, 1221 (1997) https://doi.org/10.1116/1.589442

[42] M.S.P. Reddy, H.-S. Kang, J.-H. Lee, V.R. Reddy, J.-S. Jangi "Electrical properties and the role of inhomogeneities at the polyvinyl alcohol/n-InP Schottky barrier interface”, J. Appl. Polym. Sci., 131, 39773 (2014) https://doi.org/10.1002/app.39773

[43] J.H. Werner, H.H. Güttler, "Barrier inhomogeneities at Schottky contacts", J. Appl. Phys., 69 (3), $1522-$ 1533 (1991) https://doi.org/10.1063/1.347243

[44] J.H. Werner, and H.H. Guttler, “Transport properties of inhomogeneous Schottky contacts”, Phys. Scr. T39, 258 (1991) https://doi.org/10.1088/0031-8949/1991/T39/039

[45] Ç. Bilkan, Y. Badali, S. Fotouhi-Shablou, Ş. Altındal, "On the temperature dependent current transport mechanisms and barrier inhomogeneity in Au/SnO2-PVA/n-Si Schottky barrier diodes”, Appl. Phys. A, 123, 560 (2017) https://doi.org/10.1007/s00339-017-1168-y

[46] Z. Khurelbaatar, Y.-H. Kil, K.-H. Shim, H. Cho, M.-J. Kim, Y.-T. Kim, C.-J. Choi, “Temperature Dependent Current Transport Mechanism in Graphene/Germanium Schottky Barrier Diode", Journal of Semiconductor Technology and Science, 15 - 1, 7-15 (2015) https://doi.org/10.5573/JSTS.2015.15.1.007

[47] V.V. Krongauz, E.R. Schmelzer, R.M. Yohannan, "Kinetics of anisotropic photopolymerization in polymer matrix", Polymer, 32 (9), 1654 (1991) https://doi.org/10.1016/0032-3861(91)90402-5 